\title{
New Clinical Initiatives at the Steno Diabetes Center Odense and in the Region of Southern Denmark
}

\author{
Michael E Røder*, Maria Skovlund Herreborg and Jan Erik Henriksen \\ Steno Diabetes Center Odense, Odense University Hospital, Denmark
}

*Corresponding author: Michael E Røder, Associate Professor, Steno Diabetes Center Odense, Odense University Hospital, Denmark

\begin{abstract}
In general, patients with diabetes still have an increased mortality risk, increased risk of micro- and macro-vascular complications and a decreased quality of life. Despite better options for treatment and care, to many diabetes patients are still not in optimized treatment control in order to avoid complications. In Denmark there is a long tradition for focused diabetes treatment and care, as well as research and manufacturing insulin and other antihyperglycemic drugs. Five Steno Diabetes Centers, one in each region of Denmark, have emerged as a part of the Danish Health Care System. The overall aim for these centers is to provide optimized treatment and care for all patients with diabetes regardless of age, type of diabetes, co-morbidity and where in the Health Care System the patient is treated. The vision is to provide treatment, research and education at the highest international level in the future. Steno Diabetes Center Odense is a new diabetes center which will attempt to realize this aim and vision for patients with diabetes and health care professionals in the Region of Southern Denmark. In this paper we describe the present and forthcoming new clinical initiatives at Steno Diabetes Center Odense and at its partner hospitals in the Region of Southern Denmark, which is planned or in the process of implementation.
\end{abstract}

\section{Introduction}

The Danish physician Hans Christian Hagedorn (1888-1971) initiated the industrial production of insulin in Denmark in 1923 together with the Danish physiologist August Krogh (1874-1949) by founding the company Nordisk Insulin Laboratorium, which much later merged into the pharmaceutical company Novo Nordisk A/S [1]. Further in 1936, Hans Christian Hagedorn co-discovered the principle of addition of protamine to insulin, in order to protract its time of action [2]. This principle has been marketed and in use since 1946, known as Neutral Protamine Hagedorn insulin (NPH insulin). The initial idea of Nordisk Insulin Laboratorium was to ensure the availability of insulin for the patients, and to support research, treatment and care of patients with diabetes. Thus, Hans Christian Hagedorn founded Steno Memorial Hospital in 1932, a private-based hospital solely for treatment and care of patients with diabetes. In 2017, Steno Memorial Hospital, now called Steno Diabetes Center Copenhagen, was entrusted from Novo Nordisk A/S to the National Danish Health Care System, for future treatment and care of patients with diabetes in the Capital Region of Denmark. At the same time, the Novo Nordisk Foundation granted a donation of approximately 1 billion euros to support the foundation and development of similar Steno Diabetes Centers in the other four regions of Denmark, thus covering the entire Denmark with specialized centers within prevention, treatment, care and research in diabetes. During 2018, four diabetes centers have been formed: Steno Diabetes Center Odense (SDCO), Steno Diabetes Center Århus (SDCA), Steno Diabetes Center of Northern Jutland (SDCN) and Steno Diabetes Center Zeeland (SDCS)(Figure 1). All centers are attached to general hospitals in which most other specialties are present. The grant from the Novo Nordisk Foundation also covers new buildings, which will be built and specially designed to future management of diabetes care and treatment, comprising treatment of both children and adults, in addition to diabetes research and education of health care professionals.

\section{Steno Diabetes Center Odense}

SDCO was founded January 1st, 2018 and is currently taking care of approximately 3200 patients with all kinds of diabetes. The four core activities of SDCO are: prevention and treatment of diabetic complications, clinical research, education of health care professionals and cross-sectorial collaboration between the different health care sectors. The overall aim is to provide the highest international level of treatment, care and research within diabetes, in order to give patients with diabetes in the future 
a lifespan and quality of life not different from the population without diabetes. SDCO will have the overall responsibility for the quality and treatment and care of patients with diabetes for the whole diabetes population of the Region of Southern Denmark, which is currently approximately 56.000 patients with diabetes [3], regardless of where the individual patient is treated (hospitals, outpatient clinics, primary health care providers etc).

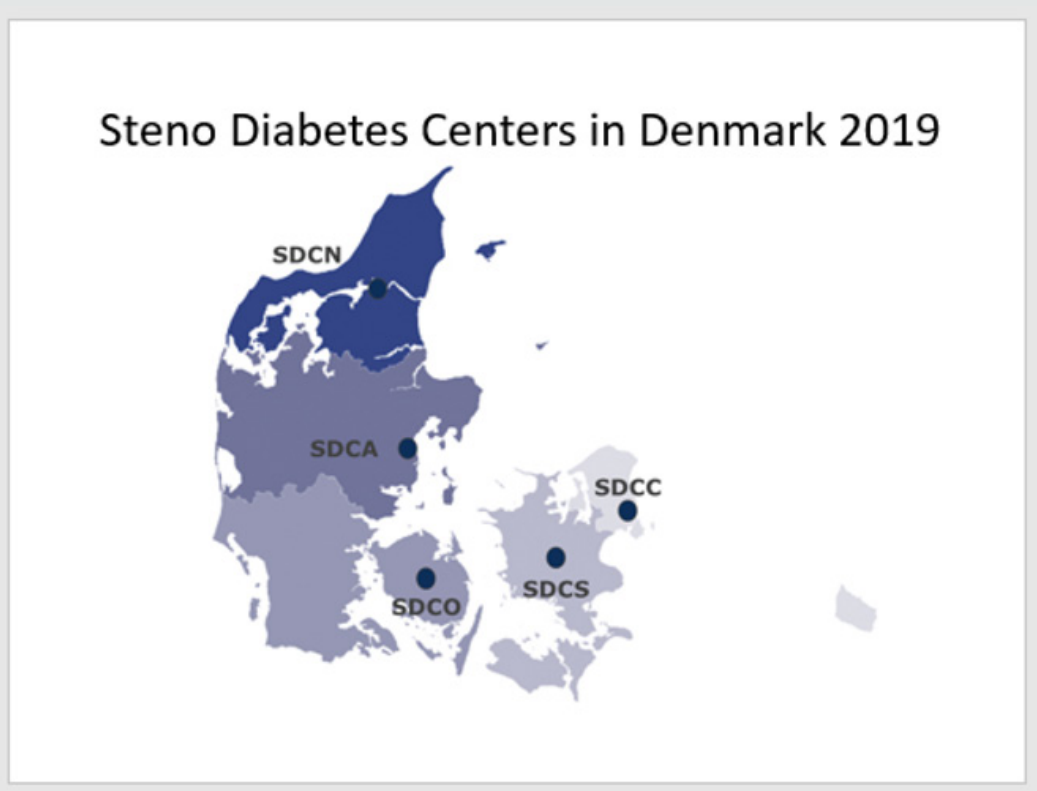

Figure 1.

To obtain the goal of ensuing and increasing the quality of patient care and treatment a close collaboration between SDCO, SDCO partner hospitals, communities and primary health care providers has to be reinforced and further developed (Figure 2). In addition to current standard treatment of patients with diabetes, numerous additional new clinical and non-clinical activities and projects will be developed and implemented within the next ten years. The standard care and treatment activities will be continued within the Regional budget, whereas the new additional activities will be covered within the grant from the Novo Nordisk Foundation.

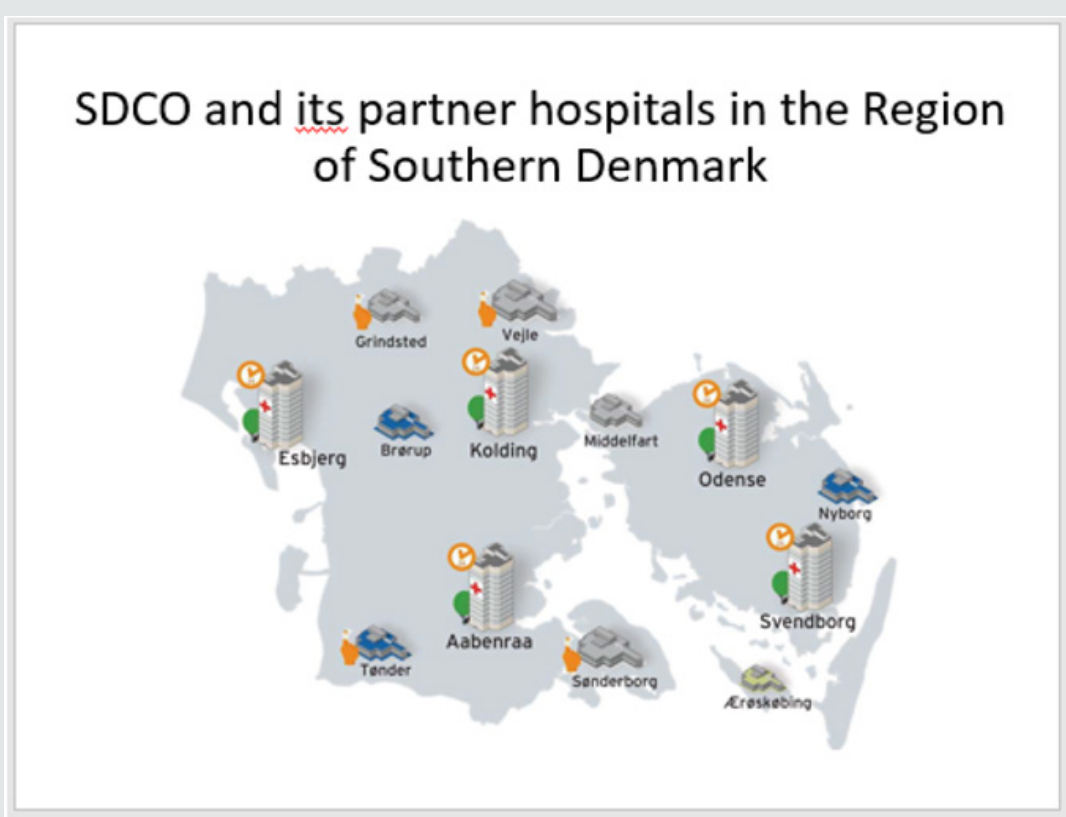

Figure 2.

Aim of Clinical Initiatives at the Steno Diabetes Center Odense

The aim of the new clinical initiatives is to add on to the current standard management of patient care and treatment at the center and its partner hospitals, and thus to improve the overall quality of patient care and treatment for all patients with diabetes in the future in the Region of Southern Denmark. 


\section{Definition of a Clinical Initiative}

The new initiatives as defined in the screenplay for SDCO is a time-limited project described in detail in a specific project description, which has to be approved in advance by the board of SDCO. Thus, the initiative runs into different phases: preparation of synopsis-approval by the board-preparation of detailed project description-approval by the board-detailed planning-initiation and implementation in the clinic-completion of the project-evaluationfinal decision to continue or not as standard care. Overall the project continues for three years. Based on evaluation of key parameters it is decided whether the initiative will continue as future standard management in the clinic or not.

\section{Approved Clinical Initiatives at SDCO Under or Awaiting Implementation}

Adults with Diabetes: Table 1 gives an overview of the various clinical initiatives which have been planned, approved and initiated from 2018 until the present date at SDCO and, for some initiatives, at the partner hospitals in the Region of Southern Denmark.

Table 1: New approved clinical initiatives from the Steno Diabetes Center Odense for patients with diabetes from 2018-19 and status of implementation in the clinic.

\begin{tabular}{|c|c|c|c|}
\hline Initiative & Short Description & Start & Expected Finalization \\
\hline $\begin{array}{l}\text { Extended opening hours in out- } \\
\text { patient clinic for adults }\end{array}$ & $\begin{array}{l}\text { Opening hours late afternoon and acute } \\
\text { appointments for patients from the emergency } \\
\text { department }\end{array}$ & 2018 & 2021 \\
\hline Diabetes psychologist for adults & $\begin{array}{c}\text { Psychologist specialized in treatment and advice } \\
\text { to patients with diabetes-related psychological } \\
\text { problems }\end{array}$ & 2019 & 2022 \\
\hline $\begin{array}{l}\text { Screening for diabetic } \\
\text { complications package }\end{array}$ & $\begin{array}{l}\text { Patients are screened for all diabetic complications in } \\
\text { one day in one place by different specialists }\end{array}$ & 2019 & 2022 \\
\hline $\begin{array}{l}\text { Screening and treatment of diabetic } \\
\text { autonomous neuropathy }\end{array}$ & $\begin{array}{l}\text { Work-up and treatment of patients with suspected } \\
\text { gastroenterological autonomous neuropathy }\end{array}$ & 2018 & 2021 \\
\hline $\begin{array}{l}\text { Screening and treatment of } \\
\text { patients with concomitant renal } \\
\text { insufficiency }\end{array}$ & $\begin{array}{c}\text { Treatment and care of patients at mutual out-patient } \\
\text { clinic visits (endocrinologist and nephrologist } \\
\text { together) }\end{array}$ & 2019 & 2022 \\
\hline $\begin{array}{l}\text { Courses for patients with } \\
\text { recurrent ketoacidosis or severe } \\
\text { hypoglycemia }\end{array}$ & $\begin{array}{l}\text { Nurse-based courses for patients with focus on } \\
\text { avoiding ketoacidosis and severe hypoglycemia }\end{array}$ & 2019 & 2022 \\
\hline $\begin{array}{l}\text { Diabetes screening and assistance } \\
\text { from diabetes team on other } \\
\text { departments }\end{array}$ & $\begin{array}{l}\text { A specialized diabetes-team (diabetes nurse and } \\
\text { endocrinologist) providing assistance to other } \\
\text { departments in the hospital for admitted patients } \\
\text { with diabetes. Opportunistic screening for unknown } \\
\text { diabetes }\end{array}$ & 2019 & 2022 \\
\hline $\begin{array}{l}\text { Coordination of patient education } \\
\text { program for children and } \\
\text { adolescents }\end{array}$ & $\begin{array}{l}\text { Assembling and coordination of different patient } \\
\text { education programs }\end{array}$ & Expected 2019 & 2022 \\
\hline $\begin{array}{l}\text { Start-up course for children and } \\
\text { adolescents with newly diagnosed } \\
\text { type } 1 \text { diabetes }\end{array}$ & $\begin{array}{l}\text { New and improved course for patients based on } \\
\text { e-learning, support and self-education }\end{array}$ & Expected 2019 & 2022 \\
\hline $\begin{array}{l}\text { Theme-based meetings for children } \\
\text { and adolescents }\end{array}$ & $\begin{array}{l}\text { New developed meetings with different themes } \\
\text { relevant for this patient group }\end{array}$ & Expected 2019 & 2022 \\
\hline $\begin{array}{l}\text { Diabetes psychologist for children } \\
\text { and adolescents }\end{array}$ & $\begin{array}{l}\text { Psychologist specialized in treatment and advice } \\
\text { to patients with diabetes-related psychological } \\
\text { problems }\end{array}$ & Expected 2019 & 2022 \\
\hline $\begin{array}{l}\text { Extended opening hours in out- } \\
\text { patient clinic for children and } \\
\text { adolescents }\end{array}$ & $\begin{array}{c}\text { Opening hours late afternoon and acute } \\
\text { appointments for patients from the emergency } \\
\text { department }\end{array}$ & Expected 2019 & 2022 \\
\hline $\begin{array}{l}\text { Diabetes screening and assistance } \\
\text { from diabetes team on psychiatric } \\
\text { departments }\end{array}$ & $\begin{array}{l}\text { A specialized diabetes-team (diabetes nurse and } \\
\text { endocrinologist) providing assistance to psychiatric } \\
\text { departments on hospital for admitted patients. } \\
\text { Opportunistic screening for unknown diabetes }\end{array}$ & Expected 2019 & 2022 \\
\hline Advice before pregnancy & $\begin{array}{l}\text { A multidisciplinary team providing advice and course } \\
\text { for women with pre-gestationel type } 1 \text { or } 2 \text { diabetes }\end{array}$ & Expected 2019 & 2022 \\
\hline $\begin{array}{l}\text { Start-up course for patients with } \\
\text { newly diagnosed type } 1 \text { diabetes }\end{array}$ & $\begin{array}{l}\text { New and improved course for patients based on } \\
\text { e-learning, support and self-education }\end{array}$ & Expected 2019 & 2022 \\
\hline Preparation before surgery & $\begin{array}{l}\text { Optimization and advice of diabetes treatment before } \\
\text { planned surgery }\end{array}$ & Expected 2019 & 2022 \\
\hline
\end{tabular}


Extended Opening Hours: The extended opening hours late afternoon every week gives patients with full-time work the possibility to have appointments in the clinic outside their working hours. In this initiative there is also an option to have acute appointments at the out-patient clinic according to the need. Thus, patients with dysregulated diabetes or newly diagnosed patients without ketoacidosis admitted to the emergency ward, do have the option to have an appointment the following day at SDCO.

Diabetes Psychologist: The American Diabetes Association guidelines for the management of diabetes [4] recommend that psycho-social support should be an integrated part of diabetes care and should be offered. Some evidence support this notion, and that psychologic intervention can result in increased acceptance of the disease, optimized self-management and a reduced number of psychological barriers towards better disease control [5-7]. In this initiative, the psychology team will provide support to the other health care professionals at SDCO and its partner hospitals to improve their understanding and management of patients with psychologic challenges in relation to their diabetes. Further, to provide individual psychologic intervention to patients with psychologic problems and challenges in relation to their diabetes, and finally develop this psychologic program to patients.

Screening for Diabetic Complications Package: The screening for diabetic complications is traditionally offered on different appointments and by different specialists on different days. In this initiative screening for all complications is done at the same day in one location. Thus, the patient meets in the out-patient clinic at SDCO and have blood and urine samples taken, ECG (patients older than 65 years). Thereafter, the patient goes to the optometrist to have a fundus-photo and an optical coherence tomography taken. The pictures will be send to an ophthalmologist for immediate evaluation and description. The patient goes to the podiatrist to have a foot examination, counseling and risk evaluation. Finally the patient is seen by the endocrinologist, who takes care of collection and evaluation of all results, give advice, change or optimize the pharmacologic treatment if needed, and plan for future treatment and visits. The whole screening package takes approximately $2 \frac{1}{2}$ hours for the patient.

Screening and Treatment of Diabetic Autonomous Neuropathy: The prevalence and incidence of diabetic complication varies and is reduced by improving glycemic control in both type 1 and type 2 diabetes $[8,9]$. Autonomous neuropathy is related to the diabetes duration. In this initiative, patients with neuropathy and suspected gastroparesis is referred to a thorough and structured workup involving both the endocrinologist and gastroenterologist, and including both endoscopy and ventricular motility tests, before eventually treatment.

Screening and Treatment of Patients with Concomitant Renal Insufficiency: Patients with diabetes complicated with diabetic kidney disease have an increased morbidity and mortality. Optimal treatment of this group of patients seems to require a team-based management approach [10]. Evidence suggests that multidisciplinary consultations with an endocrinologist, nephrologist and diabetes nurse together may improve renal outcomes in these patients [11] and that increased focus on multifactorial intervention improves long-term renal outcomes [12]. In the future multidisciplinary out-patient clinic at SDCO, patients with an estimated glomerular filtration rate (eGFR) less than $30 \mathrm{ml} / \mathrm{min}$, or between 30 and $40 \mathrm{ml} / \mathrm{min}$ and concomitant complications like acidosis, anemia, hypertension or calciumphosphate problems, will be referred to this team. Patients with progressive proteinuria will also have this opportunity.

Courses for Patients with Recurrent Ketoacidosis or Severe Hypoglycemia: Hypoglycemia is associated with an increased risk of hospital admission, falls and accidents in patients with diabetes. It can have significant physical and mental consequences and is the most important limiting factor in yielding and maintaining good glycemic control in patients with type 1 diabetes [13]. New technology such as continuous glucose monitoring systems (CGM) can have a significant effect of reducing severe hypoglycemia in patients, in particular patients with hypoglycemia unawareness. It seems that by combining CGM by focused and structured patient education do have the best outcome in minimizing the risk of severe hypoglycemia in patients with type 1 diabetes and hypoglycemia unawareness [14]. A multidisciplinary group-based patient education program with a diabetes nurse, endocrinologist, psychologist and dietician will educate and empower the patient to improve skills in order to prevent and avoid future severe hypoglycemic events. The family of the patient is included in this program, and the sessions will focus on: theory, fear of hypoglycemia, coping of unawareness, insulin adjustments, physical activity, carbohydrates and glucose sensors. These sessions can be combined with individual counseling.

Diabetes Screening and Assistance from Diabetes Team in Other Departments: Many patients admitted to the hospital for other somatic reasons such as cardiovascular disease, surgery, neurological disease and infectious diseases also have diabetes, particularly type 2 diabetes. Specialists and nurses at these departments do not always have the necessary skills and focus on care and treatment of patients with diabetes. Studies have shown that implementation of a specialized team of diabetes nurses supervised by an endocrinologist providing assistance to other departments at the hospital, can have a positive impact in reducing the length of hospitalization stay, and an increased satisfaction for both patient and health care professionals at the department [1517]. The aim of the initiative at SDCO is three-fold: optimization of care and treatment for all patients with diabetes admitted to the hospitals regardless of the department, a systematic opportunistic screening of patients with unknown diabetes by $\mathrm{HbA1c}$, and to develop and improve the skills and competences in diabetes management of the health care professionals at all departments of the hospital. Thus, in all departments where an opportunistic screening for diabetes is considered relevant based on the characteristics of the population, all patients will at the time of admittance have a blood sample taken to be analyzed for HbA1c. In patients with unknown diabetes who have an increased $\mathrm{HbA1c} \geq 48$ $\mathrm{mmol} / \mathrm{mol}$, will have this re-tested and if confirmed, the specialized diabetes team will be involved to evaluate and manage the patient. The diabetes nurse will provide assistance to all patients with 
known diabetes where the department requests assistance and help in diabetes management. The team from SDCO will provide continuous training and regular theme-based courses for the health care professionals at these departments.

As an add-on to the above described initiative, a project including a clinical pharmacist intervention is considered. Recent studies suggest that a pharmacist-driven medication review, patient interview and follow-up in patients admitted to the acute admission ward may reduce the rate of readmissions and emergency department visits in these patients [18]. The proposed project is to include a clinical pharmacist to intervene in all in-patients who have significant pharmacologic treatment changes during the hospital admission. The intervention will include a medication review and evaluation, a patient motivational interview and follow-up with the primary health care sector after discharge from hospital.

Diabetes Screening and Assistance from Diabetes Team in Psychiatric Departments: The patients with diabetes and psychiatric co-morbidities constitute a particular challenge. Psychiatric patients have a two- to four-fold increased prevalence of diabetes and the metabolic syndrome compared to the general population. Patients with severe psychiatric diseases and diabetes have a significant increased mortality [19]. As previously described studies of admitted patients with somatic disease support the impact of a specialized diabetes team providing assistance to departments [15-17]. In this initiative, a specialized nurse-based diabetes team will provide assistance to health care professionals at the psychiatric departments and in the regional out-patient psychiatric clinics, in the management and care of patients with diabetes. As for the non-psychiatric departments, the team from SDCO will provide continuous training and regular theme-based courses for the health care professionals at the psychiatric departments. The diabetes nurse in this initiative will be supervised by an endocrinologist.

Advice before Pregnancy: Fertile women with diabetes have an increased risk of giving birth to a child with malformations and pregnancy complications if their glycemic control is not optimized before conception. Optimized glycemic control before and during pregnancy reduces the risk for diabetic complications, severe hypoglycemia, preterm delivery, macrosomia and malformations and neonatal hypoglycemia. In this initiative women with a wish of pregnancy in the near future and having either type 1 or type 2 diabetes and ethnicity other than Danish are offered a program with multidisciplinary advice covering adjustment of medicine, co-morbidity, goal of treatment, injection technique, blood glucose measurement, carbohydrate counting, vitamin supplements and complication screening. This program will be provided by the endocrinologist, diabetes nurse and dietician. In addition the women are offered a group-based program covering planning of pregnancy and follow-up during and after pregnancy.

Start-Up Course for Patients with Newly Diagnosed Type 1 Diabetes: For patients with type 1 diabetes previous studies show that intensively treated patients have a significant better long-term outcome with a reduced incidence of microvascular complications [9] and cardiovascular disease [20]. Many barriers towards optimized glycemic control can be identified such as risk and fear for hypoglycemia, insufficient knowledge of long-term consequences of the disease, acceptance problems and social challenges. Thus, it is of decisive importance that management of the patient with newly diagnosed type 1 diabetes is well-structured, thorough and individualized. At SDCO newly diagnosed type 1 diabetes patients will be followed in a 6 months 'start-up package' which will comprise a multidisciplinary team course and patient interviews, individualized and group-based, covering all elements of treatment, self-management and social significance for the patient and their relatives. The structured course will be supplemented by videos and e-learning to support empowerment and 'living the good life with diabetes' in these patients.

\section{Preparation before Surgery}

Patients with diabetes who are planned for surgery may have an increased risk of complications during or after surgery. Studies have shown that the risk of deep infections postoperatively is increased in patients with a high level of HbA1c [21], an increased risk of infections, infarctions and reduced survival is linked to perioperative hyperglycemia [22], and patients with an HbA1c above $70 \mathrm{mmol} / \mathrm{mol}$ who underwent cardiovascular surgery was found to have up to a four-fold risk of mortality [23]. A recent study found that initiating and optimizing basal insulin therapy in patients planned for cardiac surgery resulted in fewer infections postoperatively and a shorter hospitalization stay [24]. In this initiative, type 1 and type 2 diabetes patients treated with insulin are offered referral to SDCO for evaluation and optimization of insulin treatment before planned surgery. The patient will be evaluated by an endocrinologist, diabetes nurse and dietician at SDCO. Focus for evaluation, treatment and advice will be to: optimize insulin therapy and antihypertensive treatment if needed, patient advice regarding precautions related to diabetes management perioperatively, and an individualized diet plan if needed. Patients planned for orthopedic and gastrointestinal surgery will be included in this initiative.

\section{Children and Adolescents with Diabetes}

As listed in Table 1, the approved initiatives for children and adolescents with type 1 diabetes resembles those planned for adult patients with diabetes as previously described. The education programs, theme-based meetings and start-up courses will be adapted to the age-group (pre-school age, school-age below 15 years and school-age above 15 years) and adjusted to the special needs and challenges in these patients. The initiative concerning a diabetes psychologist will be distinctively different from the initiative for adults. Thus, it will comprise of systematic screening and evalulation of children and adolescents with diabetes, groupbased therapy if needed, intervention using the acceptance and commitment therapy (ACT) method, psycho-education sessions for patients and their families, and training and supervision to the health care professionals.

Planned Initiatives in Near Future at SDCO Awaiting Approval: The future initiatives in pipeline are listed on Table 2. The initiatives will cover both clinical and non-clinical initiatives and for both adults, children and adolescents with various forms of diabetes. The non-clinical initiatives are meant to support 
future management and treatment of patients, including the new clinical initiatives. Thus, a unit for the evaluation of new technology, research and development will guide the use of new technology to the right patients in order to benefit most patients taken costbenefit analyses into consideration as well. A unit for quality and follow-up will provide surveillance of key quality indicators of the patients treated at SDCO and of patients treated elsewhere in the Region of Southern Denmark, and will improve quality of patient management by providing data on the patient population and at the individual level. A mutual model for the evaluation of the above initiatives will be developed and described.

Table 2: Planned future clinical and non-clinical initiatives from the Steno Diabetes Center Odense for patients with diabetes.

\begin{tabular}{|c|c|c|c|}
\hline Initiative & Short Description & Expected Initialization & Expected Finalization \\
\hline $\begin{array}{l}\text { Screening for diabetic complications } \\
\text { package -primary health care sector }\end{array}$ & $\begin{array}{l}\text { Patients are referred from general practice and } \\
\text { screened for all diabetic complications in one day } \\
\text { in one place by different specialists }\end{array}$ & $2019 / 2020$ & 2023 \\
\hline $\begin{array}{l}\text { Treatment and care of patients with } \\
\text { concomitant rheumatic condition }\end{array}$ & $\begin{array}{l}\text { Treatment and care of patients at mutual } \\
\text { out-patient clinic visits (endocrinologist and } \\
\text { rheumatologist together) }\end{array}$ & $2019 / 2020$ & 2023 \\
\hline Follow-up visits after pregnancy & $\begin{array}{l}\text { Follow-up after successful pregnancy for patients } \\
\text { with gestational diabetes }\end{array}$ & 2019 & 2022 \\
\hline $\begin{array}{l}\text { Start-up course for patients with newly } \\
\text { diagnosed type } 2 \text { diabetes }\end{array}$ & $\begin{array}{l}\text { New and improved course for patients based on } \\
\text { e-learning, support and self-education }\end{array}$ & $2019 / 2020$ & 2023 \\
\hline Call center & $\begin{array}{l}\text { Nurse-based hot-line for patients and health care } \\
\text { professionals in the primary health care sector }\end{array}$ & 2020 & 2023 \\
\hline $\begin{array}{l}\text { Coordination and continuity in patient } \\
\text { trajectories }\end{array}$ & $\begin{array}{l}\text { Improved coordination and allocation of } \\
\text { endocrinologist as responsible for individual } \\
\text { follow-up of patients }\end{array}$ & 2019 & 2022 \\
\hline Children and families with special needs & $\begin{array}{l}\text { Improved and focused follow-up for patients and } \\
\text { families with special needs and challenges }\end{array}$ & 2019 & 2022 \\
\hline $\begin{array}{l}\text { Patient education programs for different } \\
\text { age-groups }\end{array}$ & $\begin{array}{l}\text { Differentiated patient education programs with } \\
\text { focus on the relevance and special needs for } \\
\text { different age-groups }\end{array}$ & $2019 / 2020$ & 2023 \\
\hline $\begin{array}{l}\text { Unit for technology, research and } \\
\text { development }\end{array}$ & $\begin{array}{l}\text { A unit for evaluation and advice regarding } \\
\text { new technology and developments for future } \\
\text { implementation in the clinical programs }\end{array}$ & 2019 & $\mathrm{~N} / \mathrm{A}$ \\
\hline Unit for quality and follow-up & $\begin{array}{l}\text { A unit for improvement and follow-up on various } \\
\text { defined quality indicators }\end{array}$ & 2019 & $\mathrm{~N} / \mathrm{A}$ \\
\hline Model for measurement and evaluation & $\begin{array}{c}\text { Development of a common and individualized } \\
\text { model for the evaluation of all new clinical } \\
\text { initiatives }\end{array}$ & 2019 & $\mathrm{~N} / \mathrm{A}$ \\
\hline
\end{tabular}

The future clinical initiatives await at present to be described in detail. These initiatives will elaborate and extend the already approved initiatives. Multidisciplinary out-patient clinics for patients with diabetes with concomitant rheumatic, cardiac, odontological disease and other chronic diseases are in pipeline. A package for screening of diabetes complications in one day is in pipeline covering type 2 diabetes patients who are followed in the primary health care sector by the primary health care provider, as well as extended follow-up of patients with former gestational diabetes after delivery, and a nurse-based call center for health care professionals and patients followed in the primary health care sector in the Region of Southern Denmark.

Cross-Sectorial Collaboration and Development of Competences and Skills: Hand-in-hand with the above described initiatives a thorough and structured cross-sectorial collaboration between SDCO, partner hospitals, communities and the primary health care providers is currently being developed and implemented. This includes a structured and ongoing training program and theme-based courses for all health care professionals who is taken care of patients with diabetes, in order to further develop and improve competences and skills.
Patient Involvement in the Organization and Clinical Decision-Making at SDCO: Involvement of patients with diabetes and their relatives are considered important at SDCO. It is assumed that involvement in the clinical process can facilitate transformation of knowledge and improve empowerment provided by the health care professionals. Further, the diabetes educators and health care professionals can better adapt and target education, treatment and care to the needs and resources of the individual patient. User involvement at SDCO will focus on both organization (patient board, committees, involvement in new developments etc.), and on individual patient care. Thus, involvement is planned widespread on different relevant areas as: standard patient care, new clinical initiatives, cross-sectorial collaboration, development of competences and skills and clinical research. A patient committee consisting of 15 diabetes patients and relatives of different age, gender, diabetes type, social and educational background has been established. The main purpose with this patient committee is to collaborate with and give advice to the management and health care professionals at the center concerning the future strategy. This in order to ensure that current activities and new clinical initiatives are in agreement with the needs and wishes from patients with 
diabetes, their relatives and families in the future.

\section{Summary and Conclusions}

The overall vision of the new initiatives originating from Steno Diabetes Center Odense and by potential dissemination to the whole Region of Southern Denmark embracing both the primary and secondary health care sector, is to normalize lifetime expectancy and quality of life in people with diabetes. By improving all areas of diabetes management, treatment, care and patient selfcare, it may be possible to avoid or minimize future complications in patients with diabetes irrespective of type of diabetes or concomitant disease. The new and forthcoming clinical and non-clinical initiatives will potentially help to fulfil this goal.

\section{References}

1. Deckert T (2007) Hans Christian Hagedorn (1888-1971). Ugeskr Laeger, 169: 2883.

2. Hagedorn HC, Jensen BN, Krarup NB, Wodstrup I (1984) Protamine insulinate. JAMA 251: 389-392.

3. (2019) Hvor mange har diabetes? Diabetes i Region Syddanmark.

4. Davies MJ, D Alessio DA, Fradkin J, Kernan WN, Mathieu C, et al. (2018) Management of hyperglycaemia in type 2 diabetes, 2018. A consensus report by the American Diabetes Association (ADA) and the European Association for the Study of Diabetes (EASD). Diabetologia 41(2): 26692701.

5. Winkley K, Ismail K, Landau S, Eisler I (2006) Psychological interventions to improve glycaemic control in patients with type 1 diabetes: systematic review and meta-analysis of randomised controlled trials. BMJ 333(7558): 65-68.

6. Ismail K, Winkley K, Rabe-Hesketh S (2004) Systematic review and metaanalysis of randomised controlled trials of psychological interventions to improve glycaemic control in patients with type 2 diabetes. Lancet Lond Engl 363(9421): 1589-1597.

7. Steed L, Cooke D, Newman S (2003) A systematic review of psychosocial outcomes following education, self-management and psychological interventions in diabetes mellitus. Patient Educ Couns 51(1): 5-15.

8. (1998) Intensive blood-glucose control with sulphonylureas or insulin compared with conventional treatment and risk of complications in patients with type 2 diabetes (UKPDS 33). UK Prospective Diabetes Study (UKPDS) Group. Lancet Lond Engl 352(9131): 837-853.

9. Diabetes Control and Complications Trial Research Group, Nathan DM, Genuth S, Lachin J, Cleary P, et al. (1993) The effect of intensive treatment of diabetes on the development and progression of long-term complications in insulin-dependent diabetes mellitus. N Engl J Med 329(14): 977-986

10. Tuttle KR, Bakris GL, Bilous RW, Chiang JL, et al. (2014) Diabetic kidney disease: a report from an ADA Consensus Conference. Diabetes Care 37(10): 2864-2883.

This work is licensed under Creative Commons Attribution 4.0 License

To Submit Your Article Click Here:
11. Low S, Lim SC, Wang J, Yeoh LY, Liu YL, et al. (2018) Long-term outcomes of patients with type 2 diabetes attending a multidisciplinary diabetes kidney disease clinic. J Diabetes 10(7): 572-580.

12. Oellgaard J, Gaede P, Rossing P, Persson F, Parving H-H, et al. (2017) Intensified multifactorial intervention in type 2 diabetics with microalbuminuria leads to long-term renal benefits. Kidney Int 91(4): 982-988.

13. Lavernia F, Kushner P, Trence D, Rice D, Dailey G, et al. (2015) Recognizing and minimizing hypoglycemia: The need for individualized care. Postgrad Med 127(8): 801-807.

14. Yeoh E, Choudhary P, Nwokolo M, Ayis S, Amiel SA (2015) Interventions That Restore Awareness of Hypoglycemia in Adults With Type 1 Diabetes: A Systematic Review and Meta-analysis. Diabetes Care 38(8): 1592-1609.

15. Cavan DA, Hamilton P, Everett J, Kerr D (2001) Reducing hospital inpatient length of stay for patients with diabetes. Diabet Med J Br Diabet Assoc 18(2):162-164.

16. Davies M, Dixon S, Currie CJ, Davis RE, Peters JR. (2001) Evaluation of a hospital diabetes specialist nursing service: A randomized controlled trial. Diabet Med J Br Diabet Assoc 18(4): 301-307.

17. Flanagan D, Moore E, Baker S, Wright D, Lynch P (2008) Diabetes care in hospital-the impact of a dedicated inpatient care team. Diabet Med J Br Diabet Assoc 25(2): 147-151.

18. Ravn-Nielsen LV, Duckert ML, Lund ML, Henriksen JP, Nielsen ML, et al. (2018) Effect of an In-Hospital Multifaceted Clinical Pharmacist Intervention on the Risk of Readmission: A Randomized Clinical Trial. JAMA Intern Med 178(3): 375-382.

19. Ribe AR, Laursen TM, Sandbaek A, Charles M, Nordentoft M, et al. (2014) Long-term mortality of persons with severe mental illness and diabetes: a population-based cohort study in Denmark. Psychol Med. 44(14): 3097-3107.

20. Diabetes Control and Complications Trial (DCCT)/Epidemiology of Diabetes Interventions and Complications (EDIC) Study Research Group (2016) Intensive Diabetes Treatment and Cardiovascular Outcomes in Type 1 Diabetes: The DCCT/EDIC Study 30-Year Follow-up. Diabetes Care 39(5): 686-693.

21. Cancienne JM, Werner BC, Hassanzadeh H, Singla A, Shen FH, et al. (2017) The Association of Perioperative Glycemic Control with Deep Postoperative Infection After Anterior Cervical Discectomy and Fusion in Patients with Diabetes. World Neurosurg 102: 13-17.

22. Kotagal M, Symons RG, Hirsch IB, Umpierrez GE, Dellinger EP, et al. (2015) Perioperative hyperglycemia and risk of adverse events among patients with and without diabetes. Ann Surg 261(1): 97-103.

23. Vann MA (2009) Perioperative management of ambulatory surgical patients with diabetes mellitus. Curr Opin Anaesthesiol 22(6): 718-724.

24. Piatti PM, Cioni M, Magistro A, Villa V, et al. (2017) Basal insulin therapy is associated with beneficial effects on postoperative infective complications, independently from circulating glucose levels in patients admitted for cardiac surgery. J Clin Transl Endocrinol 7: 47-53.

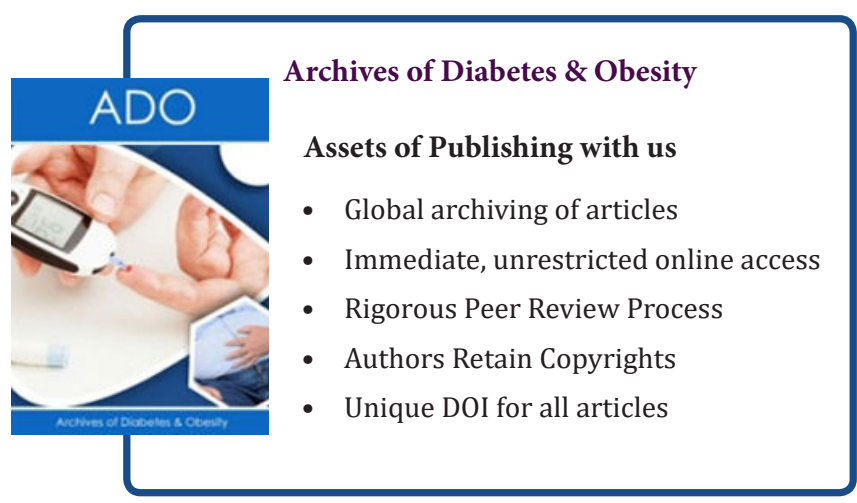

Citation: Michael E Røder, Maria Skovlund H, Jan Erik H. New Clinical Initiatives at the Steno Diabetes Center Odense and in the Region of Southern Denmark. Archives of Diabetes \& Obesity 2(2)- 2019. ADO.MS.ID.000131. DOI: 10.32474/AD0.2019.02.000131. 